\title{
Research Relationships: Collaboration, Reflection, and Sustainability in a Northern Canadian Resource Town
}

\author{
Marleny M. Bonnycastle \\ University of Manitoba \\ Maureen Simpkins \\ University College of the North
}

\begin{abstract}
The focus of this article is to share and reflect on our collaborative teaching, research, and community engagement experiences in the context of the Provincial North. We believe the university has a critical role to play in collaborative participatory research. This is particularly crucial when working in remote and northern communities in Canada that have been impacted by colonization and systemic issues such as racism and economic dependency on natural resource exploitation where prices fluctuate due to international demand.We will describe our experiences and methods of teaching, learning, and community engagement through which students, faculty, and community members engaged in community based participatory research (CBPR). The focus of this work was on the inclusion of community voices in order to share local knowledge and make decisions about future development. In this article we first describe the geographical and socio-economic context of Northern Manitoba, Canada, and the City of Thompson. We then describe the methods used (appreciative inquiry, community café consultations, photovoice, participatory mapping) to include the voices of northern female students, as well as those experiencing homelessness, in order to be included in decisions about future initiatives and programs. We conclude with reflections on our experiences of the processes of using CBPR and on its potential contribution to sustainable development (Hall \& Tandon, 2017), the importance of university-community engagement, and the contributions that can also potentially extend to communities across the Provincial North.
\end{abstract}

The Northern Review 49 (2020): 89-I I 3

https://doi.org//0.22584/nr49.2019.015 


\section{Introduction}

Traditionally, government and service providers have used a community engagement framework $(\mathrm{CEF})$ as a process to achieve various levels of community participation in addressing issues affecting people's wellbeing in a specific geographic area (Ministry of Forestry, 2013; Udofia, Noble, \& Poelzer, 2015). This framework often does not incorporate community-based knowledge generated from the local population. $\mathrm{CEF}$ is often used to gain the approval of communities instead of engaging them in knowledge generation for transformation and change. An additional issue is the tendency to separate knowledge generation from knowledge translation. Knowledge translation is the interchange of knowledge between its producers and users (Cornelissen, Mitton, \& Sheps, 2011; Powell et al., 2013). Very often, such research is for science and knowledge production, with results dissemination limited to university-based scholars. This presents a challenge for translating research into practice and policy as researchers, practitioners, service providers, policy makers, and community groups often have different needs and expectations of research (Powell et al., 2013; Young \& Borland, 2011). Community issues often require all the players to use research-informed action to address issues from different perspectives and at different levels.

Our approach to university-community engagement (UCE) is based on research that is developed in partnership with the university and the community to contribute to both knowledge generation and knowledge translation. We believe in the community's ability to address its own needs and issues that, in turn, helps researchers to understand community priorities. There are several UCE discourses and approaches that encourage community services, service-learning, community engagement, civil engagement, community-based participatory research (CBPR), and community-university research partnerships (Ahmed \& Palermo, 2010; Hall \& Tandon, 2017; Hall, Tandon, \& Tremblay, 2015; Udofia et al., 2015). The fundamental value of UCE to teaching and learning is that it integrates the three components of research, community, and teaching/ learning together to help students understand the community's social reality and to build skills and abilities that prepare them for their future practice. 
As Collins and collaborators (2007) affirm, "Community engagement is a cornerstone enabling learning, teaching and research in the post-modern world" (p. 89).

This article draws from the experience of university professors and their students, as well as from local government, service providers, and affected groups working together in the City of Thompson in Northern Manitoba. We describe the use of CBPR methods that helped engage universities and communities in addressing local and regional social and economic sustainability issues. Specific examples come from research projects with northern female students, as well as with adults and youth who are experiencing homelessness and housing instability. We document this process using Freire's "Praxis" approach (1995), which combines learning, action, and reflection in all research activities. These research activities include photovoice (Wang \& Burris, 1997), community cafés (Brown,2001), other types of qualitative methods, community-engagement approaches, and appreciative inquiry (Cooperrider \& Whitney, 2000) in order to promote dialogue, collect data, and influence changes that will reflect the experiences and needs of research participants.

These approaches are very much connected and come into play when carrying out effective CBPR. Providing opportunities for full participation of all community members is key here. When engaging in collaborative research in a northern Canadian resource town, we underscore the importance of university-community partnerships to work toward positive and healthy community change. For example, we worked with northern female students using appreciative perspectives to identify how they define their own success, as well as the factors that have made their success possible. As in other Provincial North regions, most of these students are Indigenous and face many social and economic challenges in completing a post-secondary education degree. In defining their own ideas about their "success," there is a recognition of their own capabilities as well as their contributions to citizenship and community participation. This information, in turn, informed our own teaching approaches as well as future university retention strategies. This research experience helped us to learn that our teaching role and our university location were important factors for us to explore possibilities to understand the history of research in Thompson, the community's experiences, successes, resources, capacities, needs, and interests. We then began to learn from the community, to build 
relationships and explore possibilities of working together on issues that the community saw as a priority, instead of presenting ourselves as research experts or telling them what needed to be done.

Choosing a methodological approach and designing a process to capture community perspectives and engage participants in conversations was a key starting point. We knew that it was very important to take the time to build relationships with future partners or supporters in a variety of research projects. Community café consultations helped participants to voice their experiences, knowledge, perspectives, and priorities. While many issues were discussed, it was clear that homelessness was a critical issue and it became our next project, which started by building relationships with people experiencing homelessness. Through a weekly breakfast dialogue among ourselves, research assistants, service providers, and those experiencing homelessness, we had conversations that highlighted capabilities, skills, how participants felt mistreated by society, and how they felt that they were not seen as equal citizens. We also used photovoice as a tool to talk about the life paths that resulted in homelessness (this is discussed further below). By working with adults living on the street, we were told that homelessness also affects youth in northern and remote communities. Housing instability for youth is often an invisible issue, as youth more often "couch surf" and do not consider themselves homeless because moving around from a friend's or relative's has always been part of their lives.

We have used different research methods to generate data as well as to engage students, service providers, and community in community-based participatory research processes that contribute to strengthening research capacity, which also contributes to sustainable place-relevant solutions in the long-term. The focus here is on the principles of CBPR taken to create an inclusive environment, our experiences of engaging universities and communities to work together, as well as on our successes and challenges. CBPR (Israel et al., 2008) follows principles to maximize the engagement of participants in research, as well as to promote the inclusion of their voices. CBPR also functions as an empowerment strategy as well as a vehicle for enhancing the communities in which participants live. Beyond these benefits, CBPR might further contribute to capacity building and the sustainability of communities currently affected by economic downturn and, consequently, ending poverty, which is Goal 1 of the Sustainable 
Development Goals defined by the United Nations for any community (United Nations, 2017). Although there are many advantages of CBPR, there are also challenges. Blumenthal (2011) touches on a few challenges, such as how community is defined, how community members are identified to represent community, as well as how to generate a genuine commitment to the research of the participants and keep that focus.

Our university-community engagement (UCE) approach defines the term "community" as a geographical area, one that includes its residents, service providers, representatives of public and private sectors, government, and academic institutions and their students. We have focused on the City of Thompson in Northern Manitoba, but many of the social problems there cannot be defined in isolation. The history and legacy of colonial policies continue to negatively impact First Nation communities. The traumatic destruction of traditional lands from hydro development and resource extraction, the legacy of the residential school system, and the erosion of First Nation languages and belief systems, all contribute to northern social problems. Indigenous people may experience traumatic phenomena with distinct beginnings and endings, but the ability to cope with these events is compromised by the ongoing hurt and damage that is a daily living condition (Wesley-Equimaux and Smolewski, 2004).

\section{Northern Manitoba}

Conteh (2011) describes Manitoba as "a Western province with concentrated economic activities in its commercial centre-Winnipegbut stagnation in its rural and northern areas" (p. 70). Consequently, northern economic development has historically been controlled by the provincial government, with a strong focus on meeting the needs of its dominant urban population. The City of Thompson is the largest semiurban centre in Northern Manitoba and is situated $750 \mathrm{~km}$ north of Winnipeg, located on the territory of the Nisichawayasihk Cree Nation. Thompson services an area that covers $396,000 \mathrm{~km}^{2}$, which includes thirty-two communities and approximately 72,000 people. The city acts as an economic and service "hub" for these Northern Manitoba communities, including commercial, educational, recreational, and medical services. Employment opportunities, such as the Vale nickel mine or Manitoba Hydro, also contribute to inward migration into Thompson from outlying communities (TEDWG, 2012a). Coates et al. (2014) assert, 
Of the northern provincial districts in Canada, Northern Manitoba is perhaps the least understood and least recognized by the majority of Canadians. It is a vast area, covering over two-thirds of the province, but with a small population; intense poverty; massive hydroelectric power generating capacity (which has caused substantial dislocations to the Aboriginal communities); and substantial mining activity, with several mines in operation for generations. Indeed, in the 1950s and 1960s, the combination of Inco's massive mine and smelter at Thompson, and the construction of major hydro dams across the North, gave the region a profile somewhat close to that of northern Alberta in the twentyfirst century. The excitement and attention have declined dramatically in recent decades. The North struggles for recognition within the province, let alone across the country, and has often attracted negative attention due to socioeconomic difficulties within the Aboriginal communities. (p. 25)

Shrivastava and Kennelly (2013) maintain that "PBEs [place-based enterprises], whose resources, productive activities, and ownership are anchored in specific local places, and who themselves possess a sense of place, may be more likely than conventional enterprises to pursue locally beneficial economic, social, and environmental outcomes" (p. 83). Zapf (2009) complements this statement by stating:

... humankind faces global environmental threats to our continued existence. Individuals, families, and groups face challenges of living meaningful lives within the resource realities of diverse locations at the micro-level. Social work would do well to consider a more dynamic metaphor of 'people as place' for our work in the $21^{\text {st }}$ century. (181)

Thompson is an economic hub for Northern Manitoba, a place where many people converge with different needs and cultural backgrounds. There are abundant natural resources, and economic development has been based on resource exploitation. This mix has created multiple layers of colonial interactions that have led to historic and current social and 
economic issues. As with many northern provincial regions, Thompson's economy has historically been based on resource extraction such as mining and hydroelectric development (Conteh, 2011; Southcott, 2015). Such development has generally impacted the sustainability of natural resources such as fishing, hunting, and plant gathering-particularly in the traditional territories of the region's Indigenous peoples. The diminished quality of land and water, due to pollution, flooding, and contamination, has exacerbated local social issues and has resulted in the displacement of First Nation communities. This has often led to a rise in violence and a lack of affordable and healthy housing, which, in turn, has affected the quality of life in many of the surrounding communities.

The City of Thompson itself has a relatively young population compared with other cities in Manitoba and Canada. The median age of a Thompson resident is twenty-four years compared with the provincial median of thirty-eight. The Indigenous population in Thompson is also much younger when compared to the non-Indigenous population. In 2006 , over half of the Indigenous population, or 57\%, was under the age of twenty-five, compared to just 35\% of the non-Indigenous population (Statistics Canada, 2010). In addition, 38\% of Indigenous residents in Thompson were youth under the age of fifteen, compared to just $20 \%$ of non-Indigenous residents (TEDWG, 2012b).

Starting in 1956, the City of Thompson was built by Inco in order to have a stable workforce for their nearby nickel mine. Over the decades since, the city has experienced wide population fluctuations, with an all-time population high of over 20,000 in the 1970s (FemNorthNet Project, 2012). At present, Thompson's population is estimated at closer to 13,000 people. Its economy and unique demographic make-up, as well as its isolated northern location, have presented challenges. A history of colonization has also resulted in struggles and intergenerational trauma for Indigenous people in the city and in the outlying communities and reserves. As well as Thompson's geographical location, the transient tendencies of mine workers, and the lack of accessible housing and other core social goods and services for the vulnerable segments of the city's population, add to the challenges. Thus, all these issues have impacted the City of Thompson and the surrounding communities by increasing levels of poverty and homelessness. 
Being homeless in Thompson is often depicted as a phenomenon of circular mobility, generated by the movement of residents back and forth between outlying communities and reserves and Thompson, as they are in need of medical or rehabilitation treatments, work, education, or other services and supports. Sometimes it is simply a matter of survival that brings people to the city-for example, fleeing a violent family member or being kicked out of an overcrowded house on-reserve. A lack of resources in the First Nations and northern communities often reinforces the need to move into Thompson. Mental health, domestic violence, and social issues intersect with continuous housing needs in northern communities; and in the case of Indigenous people, these issues are associated with colonization and relocation (M. M. Bonnycastle, Simpkins, \& Siddle, 2016; Christensen, 2012; Dean, 2010; Fernandez, MacKinnon, \& Silver, 2010; Hart, 2010; Kading \& Walmsley, 2018; MacKinnon, 2010; Monk, 2013).

In Northern Manitoba, experiences of social disruption can often be understood in the context of the residential school experience where young Indigenous children were taken away from their home community, often for years, and came back not knowing their language as well as not being connected with traditional activities and cultural ways of knowing and understanding (Milloy, 1999). In addition, social disruption can be attributed to relocations, flooding, and construction due to hydro development from the 1950s onward (Martin \& Hoffman, 2008; Tough, 1996). Not only did road and construction crews contribute to alcohol abuse and violence, but the flooding and relocation of communities also displaced hunters and trappers from their traditional territories, changed economic patterns and family roles, and impacted communities over several generations.

Due to the systemic nature of social and economic barriers, Indigenous people experiencing poverty and homelessness within Thompson are often dismissed as "derelicts" by the general public, and are treated with particular hostility by a segment of Thompson's population (Barker, 2013). While there is an increase in efforts to support those experiencing homelessness, the daily interaction with society is highly affected by racism and judgments on culture that perpetuate stereotypes and colonial dynamics (Graham, 2013). In a 2003 study of 100 people who identified as Indigenous in Thompson, 44\% felt that racial discrimination had limited 
their housing options at some point over the previous five years (Corrado Research and Evaluation Associates, 2003). Additional social and economic issues are increased alcohol and drug consumption, augmented economic inequalities, housing shortages and family issues, and concerns regarding possible environmental impacts and negative cultural impacts (Southcott, 2015). This perspective was often reinforced by the people we interviewed or by those who have been involved in other CBPR activities.

The two university programs involved in this university community engagement process are the University of Manitoba Northern Social Work Program (UM-NSWP) and the University College of the North Faculty of Arts, Business and Science (UCN). The social work program offers full- and part-time post-secondary education through different options that include traditional education, the ACCESS program (Alcorn \& Levin, 1998; Clare, 2013), and cohort modalities. These three options provide the opportunity for adults who have had social, economic, and cultural barriers, as well as a lack of formal education, to attain university entrance. They also enable students to take classes in or near their home communities and to integrate work-experience activities. Similarly, University College of the North offers both classroom and distancedelivery post-secondary education throughout twelve northern regional centres. In both universities, the student support model encompasses activities such as the active recruitment of Indigenous faculty and staff, northern course content, child care, Elders in Residence, peer mentoring, and scholarship and bursary programs targeting Indigenous and northern students with financial needs.

\section{Community-Based Participatory Research}

Action-oriented research is a methodological approach for doing collaborative research with practitioners and community partners, which can inform practice, programs, community development, and policies while contributing to the scientific knowledge base (Small \& Uttal, 2005). We have used community-based participatory research (CBPR) as an umbrella approach that has the power to bring people together through research activities that engage participants in data generation and community change. There are a variety of definitions of CBPR, as Schulz et al. (1998) affirm: 
There are nearly as many definitions of 'community-based' research and interventions as there are definitions of 'community.' Community may refer to geographical areas, groups that share a common history or interest, a sense of collective identity, shared values and norms, mutual influence among members, common symbols, or some combination of these dimensions. (p. 11)

Doing CBPR is about getting people together as co-researchers; it is action oriented; it is collaborative research with academics and community partners addressing their needs, issues, services, policies; and it is about building relationships through participatory methods of data generation, translation, and mobilization. By promoting the inclusion of diverse voices that contribute to different perspectives, one can formulate and respond to critical research questions and to the conceptualization of problems and their solutions informed by the research. As participants often come with different roles and identities, it is important to engage in dialogue at the same level in order to minimize power structures. When working with diverse participants - academics, social service practitioners, government authorities, youth, women, students, Indigenous people, people experiencing homelessness, people who are differently abled, and those who identify as LGBTQ - an engaging and inclusive conversation must be promoted.

Such an approach is inclusive of local people and marginalized groups and creates safe spaces for diverse voices to analyze issues; inquire about policies, inequalities, and systemic issues; identify participants' strengths, community processes, and assets; and includes diverse perspectives to collectively design strategies and actions. Our approach to universitycommunity engagement and community-based participatory research includes local cultural practices to create a safe environment for research discussions. For example, our photovoice projects, as well as our other CBPR activities, included Indigenous and local cultural practices such as having an Indigenous Elder open the event and take an active role in discussions and workshops. We also provided and shared food at the event to help to engage people in discussion while sitting around tables. Such practices have helped us to be inclusive and to build trust in a friendly natural environment that helps produce data fluidly in an authentic way. 
Next, some practical strategies will be described that can help guide the CBPR process. These include ideas on how to develop collaborative research in a way that follows academic standards and community cultural practices, which can not only achieve academic outcomes but also contribute to community action and policy development. As part of our responsibilities to this process we publish in academic journals, as well as write reports and publish articles in local newspapers, and use the media to cover community events informed by research.

\section{Appreciative Inquiry}

We use an Appreciative Inquiry (AI) philosophy and methodology, which takes the idea of social construction of reality to its positive extreme with an emphasis on relational ways of knowing and on language. AI argues that there is a tendency in our cultures to highlight the deficiencies in those who are struggling. For example, people affected by social problems are often portrayed as passive victims. Sadly, little documentation is available on people experiencing homelessness, or youth or women affected by domestic violence, or any other marginalized group as agents of change.

AI builds on generative questions to explore the participants' best experiences instead of focusing on their struggles and issues. It is based on the constructive principles of the AI approach that "the way we know affects our actions” (Cooperrider \& Whitney, 2000, p. 17). AI was used when we developed questions for interviews or community cafés or when we used photovoice. For example, in a research project on Indigenous people's voices in co-creating the concept of home (M. M. Bonnycastle, Simpkins, \& Siddle, 2016), the research team held weekly breakfast dialogues with a group experiencing homelessness. Examples of questions posed were: "What does 'home' mean to you?" "Can you tell us about your most positive association with "home"?

As well, when we interviewed northern female post-secondary students about what "success" means to them, we used an appreciative approach. Most of these students were Indigenous and faced many social and economic challenges in completing a post-secondary education degree. The following are examples of questions posed: Can you describe a moment or incident when you knew that attending university was the right path for you? .... A time when you were happy to be at university? Without being humble, please tell me what you value about yourself? Tell 
us about how you would define "success." What does success mean to you personally?

In defining and reflecting on ideas about their own success, students recognized their own capabilities as well as their contributions to citizenship and community participation. There is also an acknowledgement that their success has a ripple effect on their families and their communities. Students see that their success is intricately connected to family and community as they are seen as role models (Simpkins \& Bonnycastle, 2014).

\section{Community Café Consultations}

Over the past eight years we have conducted community café consultations on homelessness, violence against women, fetal alcohol spectrum disorder, and youth homelessness in Northern Manitoba. Perhaps one of the most poignant experiences with community café consultations took place a few months after the 2015 Point-in-Time Homeless Count in Thompson. We conducted a community café consultation: 1 ) to present the findings of the 2015 homeless count, and 2) to engage with service providers and those experiencing homelessness about key issues and future strategies. There were initially some doubts about whether it would be possible to have a participatory event where service providers, people experiencing homelessness, students, academics, and townspeople would sit side by side in group discussion. To make the event both as appealing and accessible as possible, we provided a lunch of bannock and stew; we also provided transportation from the homeless shelter and from some of the other transitional facilities to the Ma-Mow-We-Tak Friendship Centre. After our presentation of the findings and lunch, we gave everyone numbers and invited them to participate in discussion tables.

Each table was numbered and had a host and a note taker. Every fifteen minutes, participants rotated to a new table to discuss the next question. Some of the group questions were: 
- What positive changes have you seen in Thompson over the past one to three years? Describe?

- If I had a stable home I would

- What type of cultural and educational activities would you participate in?

- What services would you like to see, related to housing in Thompson?

The discussions were thoughtful, and everyone participated with $95 \%$ of participants staying until the end of the two hours. Everyone was treated equally at each table, listened to with the purpose of understanding, and given a chance to talk. By stating at the beginning of the discussion that everyone would have an opportunity to talk and would not be interrupted, participants realized and appreciated that everyone would be listened to. The stories of those experiencing homelessness were often heard for the first time. This information added greatly to the larger discussion of a community homelessness strategy. The following is an example of one of the responses from the community café consultation when racism was discussed: "Getting kicked out of buildings and off the street ... [we are] called 'bums.' There is a lack of education about why people are homeless. People need to work together to make sure they are safe, due to people going missing ...."

From the feedback we received after this community consultation, we learned that simply by the act of bringing people together and providing a space to be heard and listened to, participants were recognized and respected for their individual and collective contribution. Their role or their citizenship within this forum was not questioned but was recognized for their knowledge contribution. Everyone came away from this experience enriched and more knowledgeable about what it is like to live within the margins of a northern Canadian resource town. We used the same format after the completion of the 2016 Point-in-Time Homeless Count in Thompson (M. M. Bonnycastle, Simpkins, Bonnycastle, McKay, \& Hayter, 2016), with similar success. 


\section{Photovoice}

Photovoice is one of many approaches under the umbrella of CBPR that has been used to empower marginalized community members to work together to "identify, represent and enhance their community through a specific photographic technique" (Wang \& Burris, 1997, p. 369). The photovoice approach also offers pedagogical strategies to involve students to work with marginalized populations as part of course work. It also offers practical research methods for students to learn CBPR. Bonnycastle \& Bonnycastle (2015) commented on their experience in using photovoice with students:

Students attended a photovoice methodology workshop in which they learned about the ethics, the methodology and the process to use photovoice to capture images of 'hidden homelessness' and students agreed to share the findings of this research with the agency. (p. 240)

We used photovoice in several projects and this method helped to engage participants to share their experiences and stories. When working with a group experiencing homelessness and living in a transitional facility, they took pictures that often represented how they saw themselves prior to experiencing homelessness. Their photos and accompanying stories were exhibited at a local conference (with their permission), which resulted in some emotional and positive feedback from community members. Many stated that they now saw those experiencing homelessness differently after reading their stories. They could now see that those experiencing homelessness had their own histories, families, hopes, and dreams.

We are also aware of some of the challenges to using photovoice. For example, Liebenberg comments on concerns about the "rigor in the method's application" (2018, p. 1) and possible negative impacts of publicly sharing the findings. This is one of the reasons that research ethics guidelines are so important. In our case, participants were given the choice of whether they wanted to share their information, if they wanted to share it publicly themselves, or whether they minded if someone else read their story. Most chose to share their photos and stories but they did not necessarily want to participate in a public forum. 


\section{Mapping}

Consistent with CBPR (Israel et al., 2008), participatory mapping uses geographical maps to locate different issues. The goal was to maximize engagement in the research and promote the inclusion of youth voices. Mapping also functions as an empowerment strategy as well as a vehicle for enhancing the communities in which they live (Santo, Ferguson, \& Trippel, 2010). It was used in this research to identify barriers and factors that might contribute to youth homelessness and housing instability, as well as to include youth voices to identify other needs and gaps from their own perspective. This spatial data complements other data gathered through surveys and interviews about physical spaces that are important for youth in terms of risks or supports. We used a large map of the Thompson area, along with coloured pins and sticky notes (similar to flags) to locate places youth feel most at home, where they don't feel safe, where they gather with friends, where they go for help when needed, and other places they feel are important for youth. This discussion was enhanced by using this map of Thompson, which encouraged the youth to share their life stories related to particular locations. The youth involved in this exercise showed significant knowledge about the places and stories they are familiar with. Those stories have been recorded and analyzed by youth participants.

\section{Getting to Praxis: Some Reflections}

Being included in the society in which one lives is vital to the material, psychosocial, and political aspects of empowerment that underpin social well-being and equitable health (World Health Organization. (Commission on Social Determinants of Health, 2008, p. 33)

The approaches previously outlined reflect ways of "getting to praxis"from learning, to action and reflection. They provide ways for participants to develop new skills and promote equity and inclusion as well as acknowledge that we all have much to offer. All experiences and perspectives represent local knowledge that is often the foundation of any discussion or decisions regarding community change. For example, understanding the perspective of people experiencing homelessness and how they define the term "home" provided us with crucial insight into how they exert agency within their 
lives (often as a matter of survival and well-being). Such insight can push policy makers, service providers, advocates, and others to think beyond the norm in addressing homelessness. Moore (2007) affirms this by stating:

The social, physical and individual contextualization is increasing and broadening with a greater research focus on homeless people themselves, their motivations, daily activities, choices and desires. To understand the homeless experience, it is necessary to accept that people find ways of coping that demand respect. It may be our discomfort rather than theirs that has led to a focus on the absence in this experience, rather than the presence. $(2007$, p. 152)

Moore points out, in the case of people experiencing homelessness, that it is imperative that their lived experience of homelessness becomes a key part of the CBPR. Thus, it becomes important to find new ways to engage with people on their own terms and to take the time necessary to develop trusting relationships and capabilities that will build self-esteem.

As described earlier in this article, the use of photovoice, community café consultation, mapping, and an appreciative approach are ways to include the voices of those experiencing homelessness. When using photovoice, a group experiencing homelessness decided which pictures to take, what the accompanying story would be, and how and where the story would be told, as well as what they wanted service providers and policy makers to know. Similarly, the use of community cafés on the issue of homelessness and youth experiencing homelessness and housing instability provided a forum for everyone to be heard, especially those with a lived experience of homelessness.

As outlined in the introduction, the partnership between the University College of the North and the University of Manitoba's Northern School of Social Work was a new one in 2011. Part of the mission statements of both universities is to serve the surrounding communities. Slowly, throughout the past eight years, these two universities have partnered to educate northerners on the possibilities for collaborative research. Issues such as adult and youth homelessness, female student success, and violence against women have been a focus at the community level. 
Community organizations across the North are often economically challenged and do not have the people who can take on community research. Even though Thompson is a small community, typically there are no opportunities for community groups with overlapping interests to share knowledge and dialogue about the future. Many participants mentioned that bringing people together was beneficial in terms of future economic and community development sustainability. Many groups who had previously never worked with universities, have now partnered on many projects producing community action plans, encouraging debates, and the generation of research data and statistics.

Service providers have developed new relationships, have become closer to the universities, and have started using and learning communitybased research methods to inform their practice. We saw examples of this with the agencies that work with those experiencing homelessness in Thompson. After two years that included several gatherings, community café consultations, as well as a photovoice project, the City of Thompson asked us to conduct a Point-in-Time (PiT) Homeless Count that would provide much-needed statistics to the city. This research added to and complemented the more qualitative community-based research that we had carried out (M. M. Bonnycastle, Simpkins, Bonnycastle, \& Matiasek, 2015). Both universities coordinated two PiT homelessness counts and, after the authors of this article left from Thompson, a third PiT homelessness count was conducted.

This is a clear example of a community-based particiaptory reserach contribution to the development of northern communities and may be an example of how our learning can be shared with other communities in the Provincial North. Across the North small communities often lack the skill and resources to carry out much-needed research, prepare funding proposals, or conduct community consultations. For example, using CBPR to complement the federal government's efforts in developing PiT homelessness counts is a way for communities to engage students, agencies, lived-experience people, and other community members to work together in a participatory way instead of working in the traditional top-down research approaches. Thus, CBPR could be used in diverse environments to engage diverse groups of people working towards the same goal of "home for all," which is important to consider within the context of sustainable development (United Nations, 2017). As affirmed by Saxinger 
(2018) "North American Indigenous communities increasingly demand a community-based participatory research (CBPR) approach to social and natural sciences research undertaken on their traditional territories" (p. 187).

A consequence of the developing relationships between the universities and community agencies was also the acknowledgement of the importance of research ethics. Today, local agencies and organizations are familiar with consent forms and the OCAP (Ownership, Control, Access, and Property) principles (FNIGC-CGIPN, 2016) are now followed. The partnerships that were created to work on the issue of homelessness in Thompson meant that there was a need for community education on ethics protocols as well as community based participatory research protocols that included community and cultural practices. Submitting research ethics applications to both universities took some time at the beginning of the projects, but agencies soon understood their value and this added to the credibility of the university researchers. Also, conversely, the universities have opened their doors further and have seen the value of partnering with the community to engage in discussion and of conducting research that looks at communitybased sustainable solutions to the many social issues that northerners face.

We have also been able to use funding from institutions to develop research as well as to supplement these sources with funding from provincial and federal grants. On each of our projects we received funding from many sources at national, provincial, and institutional levels. These grants were often intended for community partnerships. For example, University College of the North faculty members can apply for small seed-grants for research that focuses on local issues and involves local community members on an equal basis. Any money paid out as salary must go to either student research assistants or local community members. Our CBPR approach and findings have also been the cornerstone for attracting new researchers to join our efforts and continue to the next steps in projects we have initiated. An example is the "Building Futures" study, which was a community-driven collaboration led by three communitybased organizations on youth transitioning out of Manitoba Child and Family Services, and homelessness prevention. We have been working with the lead researcher of this study to use the youth homeless count we developed in 2016 (M. M. Bonnycastle \& Simpkins, 2017), as well as to use our methodological approaches to community engagement. 
In terms of challenges and limitations, our university-community engagement has been successful in a variety of ways; however, sometimes we struggled to move beyond a workshop or event to actual sustainable changes and commitment for the long-term. For example, while we gathered valuable information from youth experiencing homelessness and housing instability, it was not within our power to strengthen or initiate educational programs (life skills, employment preparation, skills to access housing or further education or training), particularly for youth who will soon be aging out of the foster care system-one of the issues identified by youth but connected to policies and funding that is difficult to change. When you bring people together from different agencies and programs, each with their own mandate, it is often difficult to meet consistently and work towards long-term goals. Typically, everyone is overworked and dependent on insecure or short-term funding sources. The other challenge is simply that conducting CBPR takes time (Saxinger, 2018). It takes time to develop and build trust and relationships, and to work authentically with groups of people.

To conclude, we want to summarize our article by borrowing Hall, Tandon, and Tremblay's (2015) words. They reflect on the importance of university-community engagement:

Universities have long considered knowledge produced by universities as the best and most legitimate. But in the face of global crises that challenge humanity's capacity to respond, the value of alternative forms and paradigms of knowledge is being revisited. As the ability of the technicalrationalist knowledge long-favoured and reproduced by universities is questioned for its adequacy for the current moment, researchers are increasingly moved to work with organizations and communities outside of the university in order to co-generate knowledge which draws dynamically on multiple epistemologies and life worlds. Such cocreative acts of knowledge production are at the heart of the university's contribution to deepening knowledge democracy and cognitive justice. (p. 6) 
University-community engagement in its many forms, has become a well acknowledged approach to deepening relationships with the surrounding community and using university resources to benefit everyone. In the context of the Provincial North, both universities and communities can benefit from working together, focused on place-relevant research with the goal of economic and social sustainability (Shrivastava \& Kennelly, 2013; Zapf, 2009). Hopefully some of the small initiatives described in this article might represent some innovative ways to encourage dialogue and community input on issues of local significance in a variety of locations.

\section{Acknowledgements}

We are pleased to acknowledge the generous financial support of the CommunityUniversity Research Alliances (CURA) program of the Social Sciences and Humanities Research Council through the Manitoba Research Alliance project "Transforming Aboriginal and Inner-city Communities." We also received a SEED grant from the University College of the North, as well as a SSHRC Partnership Grant "Urban Aboriginal Knowledge Network: Research for a Better Life." The funding was administered by the Prairie Research Centre of the Urban Aboriginal Knowledge Network.

We thank the numerous participants including policy makers and decision makers, service providers, community members; and the students, faculty, and staff from the University of Manitoba Northern Social Work Program and the University College of the North. We are immensely grateful to the youth and adults who participated in different community cafés, photovoice projects, interviews, surveys, and workshops for their thoughtful participation and engagement.

A special acknowledgement goes to Elder Jack Robinson who has always been a valuable part of the research team. He brings his wisdom and personal experience. Much appreciation goes to all our research assistants for their enormous support and dedication.

Finally, we want to acknowledge the support of our two universities when conducting this collaborative research: The University of Manitoba Northern Social Work Program and the University College of the North, Faculty of Arts, Business and Science. We want to thank Professor Colin Bonnycastle for his companionship, support, and editing skills during the development of our projects and the revision of our reports. We also thank the Research Ethics Boards (REBs) from both universities for reviewing and approving the ethics applications in a timely manner, which allowed us to undertake different studies within a tight schedule. 


\section{References}

Ahmed, S. M., \& Palermo, A.G.S. (2010). Community engagement in research: Frameworks for education and peer review. American Journal of Public Health, 100(8), 1380-1387. https://doi.org/10.2105/AJPH.2009.178137

Alcorn, W., \& Levin, B. (1998). Post-secondary education for Indigenous populations. Paper presented at the International Congress on Social Welfare. Retrieved from https://files.eric.ed.gov/fulltext/ED423098.pdf

Barker, J. (2013, September 9). Rick Oberdorfer letter on behalf of Thompson Unlimited board of directors' advocates public shaming of intoxicated. Thompson Citizen. https://www.thompsoncitizen.net/news/thompson/rickoberdorfer-letter-on-behalf-of-thompson-unlimited-board-of-directorsadvocates-public-shaming-of-intoxicated-1.1366330

Blumenthal, D.S. (2011). Is community-based participatory research possible? American Journal of Preventive Medicine, 40(3), 386-389. https://doi. org/10.1016/j.amepre.2010.11.011

Bonnycastle, M.M., \& Bonnycastle, C.R. (2015). Photographs generate knowledge: Reflections on experiential learning in/outside the classroom. Journal of Teaching in Social Work, 35(3), 233-250. https://doi.org/10.1080/0 8841233.2015.1027031

Bonnycastle, M. M., \& Simpkins, M. (2017). City of Thompson youth homelessness/ housing instability - Youth Count 2016. Retrieved from http://uakn.org/wpcontent/uploads/2015/05/Youth-Count-Report-FINAL-July-7-17.pdf

Bonnycastle, M.M., Simpkins, M., Bonnycastle, C., \& Matiasek, M. (2015). 2015 Thompson, Manitoba homeless point in time count. Retrieved from http:// www.homelesshub.ca /search-resources? keywords $=\% 20$ Bonnycastle $\% 2 \mathrm{C} \% 20$ M.\&publication date $=1970-01-01 \% 2000 \% 3 A 00 \% 3 A 00$

Bonnycastle, M.M., Simpkins, M., Bonnycastle, C., McKay, T., \& Hayter, K. (2016). 2016 bomelessness partnering strategy: Point-in-time count Thompson, Manitoba. Retrieved from http://homelesshub.ca/resource/ thompson-point-time-count-2016-report

Bonnycastle, M.M., Simpkins, M., \& Siddle, A. (2016). The inclusion of Aboriginal voice in co-constructing "home": Aboriginal homelessness in a northern semi-urban community in Manitoba. In E. Peters \& J. Christensen (Eds.), The socio-cultural and geographical dimensions of Indigenous homelessness in Canada, Australia and New Zealand. University of Manitoba Press.

Brown, J. (2001). The world cafe: Living knowledge through conversations that matter. The Fielding Institute. Retrieved from https://st4.ning.com/topology/ rest/1.0/file/get/2836607717?profile=original 
Christensen, J. (2012). "They want a different life": Rural northern settlement dynamics and pathways to homelessness in Yellowknife and Inuvik, Northwest Territories. Canadian Geographer, 56(4), 419-438.

Clare, K. (2013). It's the WEC way. In J. Silver (Ed.), Moving forward, giving back: Transformative Aboriginal adult education. Fernwood Publishing.

Coates, K., Holroyd, C., \& Leader, J. (2014). Managing the forgotten north: Governance structures and administrative operations of Canada's provincial norths. Northern Review, 38, 6-54. Retrieved from https://thenorthernreview. ca/index.php/nr/article/view/324

Collins, R., Curtis, O., Curtis, S., \& Stevenson, L. (2007). Community engagement as a cornerstone enabling learning and teaching and research in the post modern world. Australian Journal of University Community Engagement, 2(1), 88-108.

Commission on Social Determinants of Health. (2008). Closing the gap in a generation: Health equity through action on the social determinants of health: Final report of the commission on social determinants of health. Retrieved from http://www.who.int/iris/handle/10665/43943

Conteh, C. (2011). Balancing resilience and adaptability: Regional development policy governance in northern Ontario and Manitoba. Canadian Journal of Regional Science, 34(2/3), 69-80.

Cooperrider, D., \& Whitney, D. (2000). A positive revolution in change: Appreciative inquiry. In D. L. Cooperrider, P. F. J. Sorensen, D. Whitney, \& T. F. Yaeger (Eds.), Appreciative inquiry: Rethinking human organization toward a positive theory of change. Stipes Publishing L.L.C.

Cornelissen,E.,Mitton,C.,\&Sheps,S.(2011).Knowledge translation in the discourse of professional practice. International Journal of Evidence-Based Healthcare. 9(2):, JUNE 2011, 9(2),184-188. https://doi.org/10.1111/j.1744-1609.2011.00215.x

Corrado Research and Evaluation Associates. (2003). Housing discrimination and Aboriginal people in Winnipeg and Thompson, Manitoba. Retrieved from https://www.worldcat.org/title/housing-discriminationand-aboriginal-people-in-winnipeg-and-thompson-manitoba/ oclc/246920933

Dean, H. (2010). Understanding human needs: Social issues, policy and practice. The Policy Press.

FemNorthNet Project. (2012). Women, economic development E restructuring in Thompson. Retrieved from http://fnn.criaw-icref.ca/images/publications/8cb 0b0b0f50c515db94493426c08abc7.pdf 
Fernandez, L., MacKinnon, S., \& Silver, J. (Eds.). (2010). The Social Determinants of Health in Manitoba. Canadian Centre for Policy Alternatives-Manitoba.

FNIGC-CGIPN. (2016). OCAP is now OCAP: Understanding the new trademark status. Retrieved from https://fnigc.ca/news/ocaptm-now-ocaprunderstanding-new-trademark-status.html

Freire, P. (1995). Pedagogy of the oppressed. Continuum.

Graham, I. (2013, October 30). KTC hosts discussion on homelessness and racism. Thompson Citizen. Retrieved from https://www.thompsoncitizen.net/news/ thompson/ktc-hosts-discussion-on-homelessness-and-racism-1.1374435

Hall, B., \& Tandon, R. (2017). Community based participatory research and sustainable development goals. Retrieved from http://unescochair-cbrsr.org/ pdf/resource/BHALL Community Based Research ENG Dec13.pdf

Hall, B., Tandon, R., \& Tremblay, C. (Eds.). (2015). Strengthening community university research partnerships: Global perspectives. University of Victoria.

Hart, M.A. (2010). Colonization, social exclusion, and Indigenous health. In L. Fernandez, S. MacKinnon, \& J. Silver (Eds.), The social determinants of health (pp. 115-125). Canadian Centre for Policy Alternatives-Manitoba.

Israel, B.A., Schulz, A.J., Parker, E.A., Becker, A.B., Allen, A.J., \& Guzman, J.R. (2008). Critical issues in developing and following CBPR principles. In M. Minkler \& N. Wallerstein (Eds.), Community-based participatory research for health: From process to outcomes (pp. 47-66). Jossey-Bass.

Kading, T., \& Walmsley, C. (2018). Homelessness in small cities: The abdication of federal responsibility. In C. Walmsley \& T. Kading (Eds.), Small cities, big issues: Reconceiving community in a neoliberal era. Athabasca University.

Liebenberg, L. (2018). Thinking critically about photovoice: Achieving empowerment and social change. International Journal of Qualitative Methods, 17,1-9. https://doi.org/10.1177/1609406918757631

MacKinnon, S. (2010). Housing: A major problem in Manitoba. In L. Fernandez, S. MacKinnon, \& J. Silver (Eds.), The social determinants of health (pp. 139149). Canadian Centre for Policy Alternatives-Manitoba.

Martin, T., \& Hoffman, S. M. (2008). Power struggles: Hydro development and First Nations in Manitoba and Quebec. University of Manitoba Press.

Milloy, J. S. (1999). A national crime. University of Manitoba Press.

Ministry of Forestry, Lands and Natural Resource Operations. (2013). A modern community engagement framework: Sharing knowledge and ideas among First Nations, communities, stakeholders and the province. Retrieved from http://www2.gov.bc.ca/assets/gov/farming-natural-resources-and-industry/ forestry/forest-health/mountain-pine-beetle/community-engagementframework.pdf 
Monk, L. (2013). Decolonizing home: A re-conceptualization of First Nations' housing in Canada (doctoral dissertation). University of Victoria.

Moore, J. (2007). Polarity or integration? Towards a fuller understanding of home and homelessness. Journal of Architectural and Planning Research, 24(2), 143-159.

Powell, K., Kitson, A., Hoon, E., Newbury, J., Wilson, A., \& Beilby, J. (2013). A study protocol for applying the co-creating knowledge translation framework to a population health study. Implementation Science, 8(98), 1-13. Retrieved from https://implementationscience.biomedcentral.com/track/ pdf/10.1186/1748-5908-8-98

Santo, C.A., Ferguson, N., \& Trippel, A. (2010). Engaging urban youth through technology: The youth neighborhood mapping initiative. Journal of Planning Education and Research, 10(1), 52-65.

Saxinger, G. (2018). Community based participatory research as a longterm process: Reflections on becoming partners in understanding social dimensions of mining in the Yukon. Northern Review, 47, 187-207. https:// doi.org/10.22584/nr47.2018.009

Schulz, A.J., Parker, E.A., Israel, B.A., Becker, A.B., Maciak, B.J., \& Hollis, R. (1998). Conducting a participatory community-based survey for a community health intervention on Detroit's east side. Journal of Public Health Management Practice, 4(2), 10-24.

Shrivastava,P.,\&Kennelly,J.J.(2013).Sustainabilityandplace-basedenterprise.Organization E environment, 26(1), 83-101. https://doi.org/10.1177/1086026612475068

Simpkins, M., \& Bonnycastle, M. M. (2014). "We're in this together": Factors that influence and support success for female post-secondary students in northern Manitoba, Canada. 2014 Arctic Yearbook. Retrieved from http:// www.arcticyearbook.com/index.php/toc2014

Small, S.A., \& Uttal, L. (2005). Action-oriented research: Strategies for engaged scholarship. Journal of Marriage and Family, 67(4), 936-948. https://doi. org/10.1111/j.1741-3737.2005.00185.x

Southcott, C. (2015). Resource development and northern communitiesAn introduction. Northern Review, 41, 3-12. https://doi.org/10.22584/ $\underline{\mathrm{nr} 41.2015 .001}$

Statistics Canada. (2010). Canada year book. Retrieved from https://www150. statcan.gc.ca/n1/pub/11-402-x/11-402-x2010000-eng.htm

TEDWG. (2012a). Education and training action plan. Retrieved from http:// www.thompson.ca/modules/showdocument.aspx?documentid $=563$ 
TEDWG. (2012b). Housing action plan: Final report. Retrieved from https://thompson.municipalwebsites.ca/Editor/images/documents/ TEDWG/121108\%20-\%20Housing\%20Action\%20Plan FINAL[1].pdf

Tough, F.J. (1996). As their natural resources fail: Native peoples and the economic bistory of northern Manitoba. UBC Press.

Udofia, A., Noble, B., \& Poelzer, G. (2015). Community engagement in environmental assessment for resource development: Benefits, enduring concerns, opportunities for improvement. Northern Review, 39, 98-110. Retrieved from https://thenorthernreview.ca/index.php/nr/article/view/392/422

United Nations. (2017). Sustainable development goals. Retrieved from https:// sustainabledevelopment.un.org/?menu=1300

Wang, C., \& Burris, M.A. (1997). Photovoice: Concept, methodology, and use for participatory needs assessment. Health education \& behavior, 24(3), 369-387.

Wesley-Esquimaux, C.C., \& Smolewski, M. (2004). Historic trauma and Aboriginal healing. Retrieved from http://www.ahf.ca/downloads/historictrauma.pdf

Young, D., \& Borland, R. (2011). Conceptual challenges in the translation of research into practice: It's not just a matter of "communication." Translational behavioral medicine, 1(2), 256-269. https://doi.org/10.1007/ s13142-011-0035-1

Zapf, M.K. (2009). Social work and the environment: Understanding people and place. Canadian Scholars' Press Inc.

\section{Authors}

Marleny Bonnycastle is associate professor with the Faculty of Social Work at the University of Manitoba.

Maureen Simpkins is associate profeesor with the Department of Aboriginal and Northern Studies at the University College of the North in Thompson, Manitoba. 